ISSN 2466-2232 (Print)

ISSN 2466-2100 (Online)

\title{
최근 $\mathrm{SnBi}$ 계 저온 솔더 합금 및 접합 특성
}

\author{
강 혜 준* 백 범 규 ${ }^{* *}$ 정 재 필*,† \\ *서울시립대학교 신소재공학과 \\ **경동엠텍
}

\section{Recent Low Temperature Solder of SnBi and Its Bonding Characteristics}

\author{
Hyejun Kang*, Bumgyu Baek** and Jae Pil Jung*, \\ *Department of Materials Science and Engineering, University of Seoul, Seoul, 02504, Korea \\ **KD MTEC Co. Ltd., Asan, 31402, Korea
}

†Corresponding author : jpjung@uos.ac.kr

(Received July 31, 2020 ; Revised September 2, 2020 ; Accepted October 5, 2020)

\begin{abstract}
A solder has been extensively used for long time in electronics packaging field, and there are various Sn-based lead-free solders such as $\mathrm{Sn}-\mathrm{Ag}-\mathrm{Cu}, \mathrm{Sn}-\mathrm{Cu}, \mathrm{Sn}-\mathrm{Bi}$ and etc. Recently, the low temperature solder, typically Sn$58 \mathrm{wt} \% \mathrm{Bi}-\mathrm{X}$ alloys, attract attention from industry because of flexible printed circuit board (FPCB) application and to avoid bending or warpage of big size electronic devices after high temperature soldering. In the $\mathrm{Sn}-58 \mathrm{wt} \% \mathrm{Bi}-\mathrm{X}$ solder, basic important issues are melting temperature, wettability, microstructure, mechanical properties and etc. Specifically, the $\mathrm{Sn}-58 \mathrm{wt} \% \mathrm{Bi}-\mathrm{X}$ solder receives much attention to improve the brittleness by grain refinement of Bi-phase. In this paper, recent studies about $\mathrm{Sn}-58 \mathrm{wt} \% \mathrm{Bi}-\mathrm{X}$ solders were reviewed including melting temperature, microstructure and mechanical properties.
\end{abstract}

Key Words : Solder, Sn-58wt\%Bi, Melting temperature, Microstructure, Mechanical property

\section{1. 서 론}

전자 산업이 시작된 이래로 솔더링 공정은 모든 전자 제품 조립에 있어 가장 기본적인 접합 기술로 자리 잡 고 있으며, 패키징 기술의 출현과 함께 솔더링의 적용 이 더욱 증가하고 있다. 솔더링이란 융점 $450^{\circ} \mathrm{C}$ 미만 의 용융된 솔더 (solder)를 모재 (피접합재)의 틈새에 침투 및 퍼지게 하여 접합하는 방법이다 ${ }^{1)}$. 솔더링은 접합기술의 일종이지만 비슷한 용융용접과 구별되는 점 은 공정 중 모재는 용융되지 않고 솔더만 용융되어 접 합이 이루어지며 솔더링된 모재와 솔더 사이에 금속화 학적 결합이 발생한다는 점이다. 이러한 솔더링 기술은 미래에도 전자 부품 연결 분야에 있어서 필수적인 공정 으로 남을 것이다.

솔더의 내구성과 신뢰성은 전자 제품의 기능 및 수명
에 절대적으로 중요한 사항이므로, 견고한 접합부를 얻 기 위해서는 사용되는 솔더가 물리·화학적 특성에서 최 적화되어야 한다. 가정 및 산업용 전자제품 분야와 마 찬가지로, 최근에는 자동차용 전장품 분야에서도 무연 솔더 $\left(\mathrm{Pb}\right.$-free solder)의 적용이 요구되고 있다 ${ }^{2,3)}$. 전 자산업에서 $\mathrm{Pb}$ 함유 솔더의 사용 규제 이후, $\mathrm{Pb}$ 가 함유 되지 않은 다양한 $\mathrm{Sn}$ 계 무연 솔더가 개발되었는데, 예를 들면 $\mathrm{Sn}-\mathrm{Ag}$ 계 (대표 솔더 $\mathrm{Sn}-3.5 \% \mathrm{Ag}$, 융점 $221^{\circ} \mathrm{C}$ ), $\mathrm{Sn}-\mathrm{Cu}$ 계 $\left(\mathrm{Sn}-0.7 \% \mathrm{Cu}\right.$, 융점 $\left.227^{\circ} \mathrm{C}\right), \mathrm{Sn}-\mathrm{Ni}$ 계 $\left(\mathrm{Sn}^{-}\right.$ $0.1 \% \mathrm{Ni}$, 융점 $\left.231^{\circ} \mathrm{C}\right), \mathrm{Sn}-\mathrm{Zn}$ 계 $\left(\mathrm{Sn}-9 \% \mathrm{Zn}\right.$, 융점 $\left.198^{\circ} \mathrm{C}\right)$, $\mathrm{Sn}-\mathrm{Bi}$ 계 $\left(\mathrm{Sn}-58 \% \mathrm{Bi}\right.$, 융점 $\left.139^{\circ} \mathrm{C}\right), \mathrm{Sn}-\mathrm{Ag}-\mathrm{Cu}$ 계( $\mathrm{Sn}-$ $3 \% \mathrm{Ag}-0.5 \mathrm{Cu}$, 융점 $217^{\circ} \mathrm{C}$ ), $\mathrm{Sn}-\mathrm{In}$ 계 $(\mathrm{Sn}-52 \% \mathrm{In}$, 융 점 $118^{\circ} \mathrm{C}$ )등의 솔더들이 있다 ${ }^{4-13)}$. 또한, 솔더의 성능 을 향상시키기 위해 최근에는 강화재료, 미량의 첨가원 소, 고분자 등을 첨가하여 신뢰성을 향상시키는 연구들 도 진행되고 있다. 
전자부품의 플렉서블(flexible), 웨어러블(wearable) 화로 인하여 전자 제품에 사용되는 연성 기판의 내열성 저하로 솔더링 후 열변형 및 열손상이 발생되기 쉬워지 고 있다. 또한 전자부품의 모듈화, 대형화로 $\mathrm{Si}$ 칩과 기 판과의 열팽창 계수 차이로 인해 높은 온도로 가열될수 록 이로 인한 전자부품의 열변형이 증가되고 접합불량 이 빈발한 실정이다. 이러한 문제를 해결하기 위하여, $\mathrm{Sn}-58 \% \mathrm{Bi}$ 계나 $\mathrm{Sn}-52 \% \mathrm{In}$ 계와 같은 접합온도가 낮은 저융점 솔더에 대한 연구의 필요성이 증가되고 있다 ${ }^{11)}$. 따라서 본 글에서는, 저온 솔더 특히 $\mathrm{Sn}-58 \% \mathrm{Bi}$ 계 솔더를 중심으로 최근의 연구 결과들을 정리하여 소개 하고자 한다.

\section{2. $\mathrm{Sn}-\mathrm{Bi}$ 계 솔더의 융점과 젖음성}

저융점 솔더인 $\mathrm{Sn}-\mathrm{Bi}$ 계는 그 용도에 맞게 낮은 융점 을 가져야 한다. 합금원소에 따라 다양한 융점과 솔더 링 특성을 갖기 때문에, 첨가 원소에 대한 연구가 필요 하다. 또, 양호한 솔더링을 위해서 솔더는 피접합재 금 속 표면에 최적의 퍼짐성과 젖음특성을 보여야 한다. 즉, 퍼짐성과 젖음성은 솔더링 시 작업성 확보를 위한 기본적 요구 조건이다.

$\mathrm{Sn} 58 \mathrm{Bi}$ 공정 솔더의 융점에 미치는 $\mathrm{Ag}, \mathrm{RE}$ 첨가 원소의 영향은 Table 1 에 보인 바와 같다. 공정 조성 인 $\mathrm{Sn} 58 \mathrm{Bi}$ 의 융점은 평형상태도 등에서 통상 138. $5^{\circ} \mathrm{C}$ 로 알려져 있다. 그러나 이 융점은 $\mathrm{Sn} 58 \mathrm{Bi}$ 합금의 가열 속도에 따라 약간의 편차가 있을 수 있다. Table 1 에서 보듯이, $\mathrm{Sn} 58 \mathrm{Bi}$ 는 $136.1^{\circ} \mathrm{C}$ (고상온도) $139.1^{\circ} \mathrm{C}$ (액상온도)의 용융 범위를 갖는 것으로 보고되 기도 한다. $\mathrm{Sn} 58 \mathrm{Bi}$ 합금에 $1 \%$ 이내의 $\mathrm{Ag}$ 를 가하여 솔더의 취성을 개선시키고, 융점을 저하시키기도 한다. $0.5 \mathrm{wt} \% \mathrm{Ag}$ 의 첨가로 융점이 $1^{\circ} \mathrm{C}$ 이하로 감소되어, $135.7^{\circ} \mathrm{C}$ (고상온도) $\sim 138.2^{\circ} \mathrm{C}$ (액상온도)의 용융 범위 를 갖는 것으로 알려져 있다 ${ }^{14)}$.

이렇게 공정온도가 범위로서 표기되는 이유는 순수 공정 조성이 아니기 때문이다. $\mathrm{Sn} 58 \mathrm{Bi}$ 는 순수 공정 조성이면 하나의 융점 온도로 나타나야 하지만 현실적 으로 산업계에서 사용하는 $\mathrm{Sn} 58 \mathrm{Bi}$ 는 순수 공정 조성 이 아니고 불순물 등이 포함되어 있어 고상온도 및 액 상온도로 나누어진다. 또한 $\mathrm{Sn}-\mathrm{Bi}$ 공정 조성은 연구자 에 따라 다른 조성도 보고되어진다. 예를 들어, 미국의 NIST (National Institute of Standard and Technology)에서는 $\mathrm{Sn}-56.97 \mathrm{wt} \% \mathrm{Bi}$ 조성을 공정 조성으 로 보고했고 ${ }^{33)}$, 어떤 연구자들은 $\mathrm{Sn}-57 \mathrm{wt} \% \mathrm{Bi}$ 를 공 정 조성으로 사용하기도 한다 ${ }^{34)}$.

$\mathrm{Sn} 58 \mathrm{Bi}$ 공정 솔더의 융점에 미치는 $\mathrm{Ag}, \mathrm{In}, \mathrm{Ag}-\mathrm{In}$ 복 합 첨가의 영향도 Table 1에 나타내었다. In은 통상 $\mathrm{Sn} 58 \mathrm{Bi}$ 공정 솔더의 연성 개선 및 융점 저하제로 첨가 된다. $3 \% \mathrm{In}$ 의 첨가로 $119.9^{\circ} \mathrm{C}$ (고상온도) $\sim 140.5^{\circ} \mathrm{C}$

Table 1 Melting temperatures of $\mathrm{Sn}-\mathrm{Bi}-\mathrm{X}$ solders (all wt\%)

\begin{tabular}{|l|c|c|c|c|}
\hline \multicolumn{1}{|c|}{ Solder } & Solidus $\left({ }^{\circ} \mathrm{C}\right)$ & Liquidus $\left({ }^{\circ} \mathrm{C}\right)$ & Mushy zone & Ref. \\
\hline $\mathrm{Sn}-58 \% \mathrm{Bi}$ & 136.1 & 139.1 & 3 & 14 \\
\hline $\mathrm{Sn}-58 \% \mathrm{Bi}$ & 139.3 & 147.6 & 8.3 & 15 \\
\hline $\mathrm{Sn}-58 \% \mathrm{Bi}$ & 139.4 & 148.0 & 8.6 & 16 \\
\hline $\mathrm{Sn}-58 \% \mathrm{Bi}-0.5 \mathrm{Ag}$ & 135.7 & 138.2 & 2.5 & 14 \\
\hline $\mathrm{Sn}-58 \% \mathrm{Bi}-0.1 \mathrm{Ag}$ & 136.2 & 139.7 & 3.5 & 14 \\
\hline $\mathrm{Sn}-58 \% \mathrm{Bi}-0.5 \mathrm{Ag}-0.1 \mathrm{RE}$ & 136.6 & 139.1 & 2.5 & 14 \\
\hline $\mathrm{Sn}-58 \% \mathrm{Bi}-3.0 \mathrm{wt} \% \mathrm{In}$ & 119.9 & 140.5 & 20.6 & 15 \\
\hline $\mathrm{Sn}-58 \% \mathrm{Bi}-4.0 \mathrm{wt} \% \mathrm{Ag}$ & 138.1 & 145.5 & 7.4 & 15 \\
\hline $\mathrm{Sn}-58 \% \mathrm{Bi}-3 \mathrm{In} 4 \mathrm{Ag}$ & 116.9 & 138.1 & 21.2 & 15 \\
\hline $\mathrm{Sn}-52 \mathrm{Bi}-1.8 \mathrm{Sb}$ & 140.6 & 152.0 & 11.4 & 16 \\
\hline $\mathrm{Sn}-44 \mathrm{Bi}-1.8 \mathrm{Sb}$ & 141.9 & 180.5 & 38.6 & 16 \\
\hline $\mathrm{Sn}-48 \mathrm{Bi}-1.0 \mathrm{Sb}$ & 140.6 & 168.7 & 28.1 & 16 \\
\hline $\mathrm{Sn}-48 \mathrm{Bi}-1.4 \mathrm{Sb}$ & 141.2 & 170.4 & 29.2 & 16 \\
\hline $\mathrm{Sn}-48 \mathrm{Bi}-1.8 \mathrm{Sb}$ & 140.9 & 172.7 & 31.8 & 16 \\
\hline $\mathrm{Sn}-48 \mathrm{Bi}-2.0 \mathrm{Sb}$ & 142.3 & 169.7 & 27.4 & 16 \\
\hline $\mathrm{Sn}-48 \mathrm{Bi}-2.4 \mathrm{Sb}$ & 142.8 & 169.3 & 26.5 & 16 \\
\hline $\mathrm{Sn}-48 \mathrm{Bi}-2.8 \mathrm{Sb}$ & 143.6 & 168.4 & 24.8 & 16 \\
\hline
\end{tabular}


(액상온도)의 용융 범위 (융점 피크온도, $133.7^{\circ} \mathrm{C}$ )를 갖는 것으로 보고되었으며 $\mathrm{Sn}-58 \mathrm{Bi}+4 \% \mathrm{Ag}$ 의 융점은 $1^{\circ} \mathrm{C}$ 이내로 강하됨을 알 수 있다. $\mathrm{Sn} 58 \mathrm{Bi}+3 \% \mathrm{In}-4 \% \mathrm{Ag}$ 복합 첨가는 $116.9^{\circ} \mathrm{C}$ (고상온도) $~ 134.1^{\circ} \mathrm{C}$ (액상온도)의 용융 범위 (융점 피크온도, $138.1^{\circ} \mathrm{C}$ )로 보고되었다 ${ }^{15)}$.

한편, $\mathrm{Sn}$ 에 $\mathrm{Sb}$ 를 첨가하면 융점이 증가하는데 이때 포정 (peritectic, $\mathrm{Sn}-6.2 \mathrm{wt} \% \mathrm{Sb}$ ) 온도는 $243^{\circ} \mathrm{C}$ 로서 $\mathrm{Sn}$ 의 융점 $232^{\circ} \mathrm{C}$ 에 비해 약 $11^{\circ} \mathrm{C}$ 높다. $\mathrm{Sn}-\mathrm{Bi}$ 솔더 에 $\mathrm{Sb}$ 를 첨가하고 $\mathrm{Bi}$ 가 감소되면 융점이 증가하는 것 으로 보고되었다 ${ }^{16)}$. 예를 들어 $\mathrm{Sn}-52 \mathrm{wt} \% \mathrm{Bi}-1.8 \mathrm{Sb}$ 의 경우 $\mathrm{Sn}-58 \% \mathrm{Bi}$ 에 비해 고상온도가 약 $4.6^{\circ} \mathrm{C}$ 정도 증 가한다. 그러나 이는 $\mathrm{Bi}$ 의 함량도 $6 \%$ 나 감소되었기에 순수한 $\mathrm{Sb}$ 의 영향이라고 판단하기는 어렵다. 한편 $\mathrm{Sn}^{-}$ $48 \mathrm{wt} \% \mathrm{Bi}$ 솔더에 $\mathrm{Sb}$ 를 $1 \%$ 에서 $2.8 \%$ 까지 첨가하면 Table 1로부터 융점이 증가함을 알 수 있다.

$\mathrm{Xu}$ 등 ${ }^{17)}$ 은 $\mathrm{Sn}-50 \mathrm{Bi}-(1 \sim 5) \mathrm{wt} \% \mathrm{Cu}$ solder에 대해 융점 및 퍼짐(spreading) 특성에 대하여 보고하였다. $\mathrm{Sn}-50 \mathrm{Bi}-5 \mathrm{wt} \% \mathrm{Cu}$ 는 약 $155^{\circ} \mathrm{C}$ 의 융점을 나타내었으 며, $4 \sim 1 \% \mathrm{Cu}$ 로 $\mathrm{Cu}$ 함량이 감소됨에 따라 융점은 약 $1 \sim 2^{\circ} \mathrm{C}$ 정도 감소되었다. $\mathrm{Bi}$ 및 $\mathrm{Cu}$ 함량을 모두 변화시 키는 경우, $\mathrm{Sn}-\mathrm{Bi}-\mathrm{Cu}$ 계 솔더의 퍼진 면적 (spreading area)은 $\mathrm{Bi}$ 함량 증가에 따라서 증가되고 최적 $\mathrm{Bi}$ 함 량 이후에는 감소되는데 최대 퍼진 면적을 보이는 최적 함량은 $\mathrm{Sn}-17 \% \mathrm{Bi}-0.5 \% \mathrm{Cu}$ 라고 보고하였다.

$\mathrm{Sn}-38 \mathrm{Bi}-1.5 \mathrm{Sb}-0.7 \mathrm{Ag}$ 솔더는 $\mathrm{Sn} 58 \mathrm{Bi}$ 솔더보다 더 우수한 젖음성과 젖음 시간을 가지고 있는 것으로 알려져 있다 ${ }^{18)}$. 예를 들어 수계 플럭스를 사용한 경우 $160^{\circ} \mathrm{C}$ 에서 $\mathrm{Sn} 58 \mathrm{Bi}$ 솔더의 웨팅 시 영점 시간 (to, zero cross time)은 약 1.2 초 내외이지만, $\mathrm{Sn}-38 \mathrm{Bi}-1.5 \mathrm{Sb}^{-}$ $0.7 \mathrm{Ag}$ 솔더는 약 0.8 초 내외로 $\mathrm{Sn} 58 \mathrm{Bi}$ 의 $2 / 3$ 에 불 과하다. 일반적으로 무연 솔더의 경우 영점 시간은 1.2 초 이내를 요구하지만 양호한 상업화 솔더는 많은 경우 1.0 초 이내를 보이고 있다. 수계 플럭스를 사용한 $160^{\circ} \mathrm{C}$ 의 조건에서 최대 젖음력은 $\mathrm{Sn} 58 \mathrm{Bi}$ 와 $\mathrm{Sn}-38 \mathrm{Bi}-1.5 \mathrm{Sb}^{-}$ $0.7 \mathrm{Ag}$ 솔더 모두 약 $0.6 \mathrm{mN}$ 으로 비슷한 값을 보이는 것으로 보고되었다. 보통 원활한 솔더링을 위해서는 (1) 용융 솔더가 모재 금속 표면을 적시며 퍼져나가는 젖음 (wetting)성이 좋아야 하고, (2) 마주보는 두 모재 금 속 사이(부품과 리드의 틈새)에 용융 솔더가 빨려 들어 가는 모세관 현상이 잘 일어나야 하며 (3) 솔더와 모재 금속 표면의 상호 원자간 이동인 확산이 빠르게 일어나 야하는 것 등 여러 조건이 우수해야 한다 ${ }^{19)}$.

\section{3. $\mathrm{Sn}-\mathrm{Bi}$ 솔더의 미세 조직}

$\mathrm{Sn} 58 \mathrm{Bi}$ 공정 솔더는 Fig. 1에서 보는 것처럼 연성

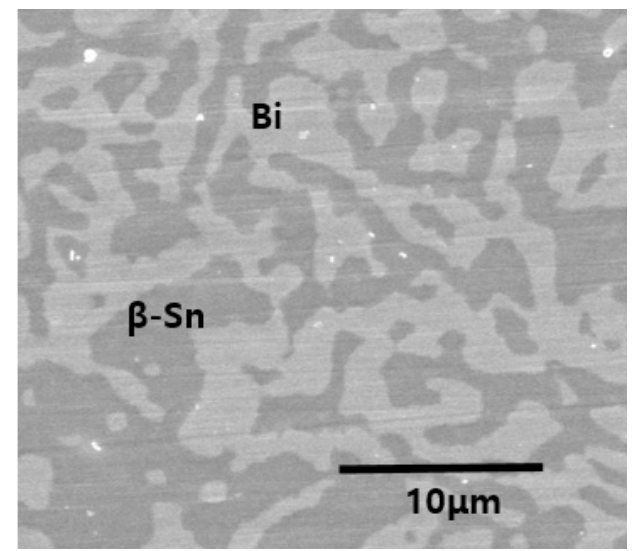

Fig. 1 Microstructure of Sn58Bi solder (photo by author)

을 갖는 어두운 색의 $\beta-\mathrm{Sn}$ 상과 밝은 색의 취성을 갖는 $\mathrm{Bi}$ 상이 혼재하여 존재한다. 두 상은 전형적인 층상형 (lamellar) 공정 조직을 가지며 $\beta-\mathrm{Sn}$ 상과 $\mathrm{Bi}$ 상이 교 대로 나타난다. 솔더의 합금원소들이 $\mathrm{Sn} 58 \mathrm{Bi}$ 미세조 직에 많은 영향을 미치는데, $1 \% \mathrm{Cu}$ 의 첨가는 $\mathrm{Sn} 58 \mathrm{Bi}$ 솔더의 결정립을 미세화하는 것으로 알려져 있다 ${ }^{20)}$. 또 Sakuyama 등 21$)$ 에 의하면 $0.5 \mathrm{wt} \%$ 의 $\mathrm{Sb}$ 의 첨가는 $\mathrm{Sn}-58 \% \mathrm{Bi}$ 솔더의 결정립의 크기를 $50 \%$ 정도로 미세 화시키며, $0.5 \mathrm{wt} \% \mathrm{Zn}$ 의 첨가는 $\mathrm{Sn} 58 \mathrm{Bi}$ 솔더의 결 정립을 조대화하는 것으로 보고하였다. 또한 Mokhtari 등 ${ }^{22)}$ 은 $0.5 \mathrm{wt} \% \mathrm{In}, 0.5 \mathrm{wt} \% \mathrm{Ni}$ 을 $\mathrm{Sn} 58 \mathrm{Bi}$ 에 첨가하 여 미세조직 및 인장 강도를 조사하였다. 이들의 연구 결과에 의하면 $\mathrm{Sn} 58 \mathrm{Bi}$ 에 $0.5 \mathrm{wt} \% \mathrm{In}$ 을 첨가한 경우, 솔더 벌크 내의 과도한 취성의 $\mathrm{Bi}$ 상의 성장을 억제하며 $0.5 \mathrm{wt} \% \mathrm{Ni}$ 을 첨가한 $\mathrm{Sn} 58 \mathrm{Bi}$ 솔더는 공정조직에 $\mathrm{Ni}_{3} \mathrm{Sn}_{4} \mathrm{IMC}$ 를 나타내고, 일부 물고기뼈 (fishbone) 같은 형태의 규칙적 공정 영역을 보이기도 한다. $\mathrm{Ni}$ 을 첨가한 경우도 $\mathrm{Sn} 58 \mathrm{Bi}$ 에 비해서 $\mathrm{Bi}$ 상의 크기가 감소 하는 것으로 보고되었다.

이러한 결과로부터 $\mathrm{Sn} 58 \mathrm{Bi}$ 솔더에 $\mathrm{Sb}, \mathrm{In}, \mathrm{Ni}, \mathrm{Ag}$ 를 $0.5 \mathrm{wt} \%$ 첨가 혹은 $\mathrm{Cu} 0.5,1.0 \mathrm{wt} \%$ 를 첨가함으로 서 결정립이 미세화 되는 것을 알 수 있으며, $0.5 \mathrm{wt} \%$ $\mathrm{Zn}$ 의 첨가는 오히려 $\mathrm{Sn} 58 \mathrm{Bi}$ 솔더의 결정립을 조대화 하는 것을 알 수 있다. 그러나 이에 대한 원인은 아직 까지 명확히 밝혀져 있지 않다.

한편, $\mathrm{Sn} 58 \mathrm{Bi}$ 솔더에 나노 분말을 적정량 첨가한 경우 에도 솔더 결정립이 미세화 된다 ${ }^{23-24)}$. 미세한 나노 분 말이 첨가된 솔더에서 나노 입자는 솔더 기지 내에서 핵생성 사이트의 역할을 한다. 이는 솔더 응고 시 많은 고체 핵생성이 일어나게 하여 접종제로 작용함으로서 솔더 조직의 상(phase)이 미세화가 되도록 한다.

나노입자가 솔더 기지의 상(phase) 미세화에 미치는 영향을 정량적으로 조사하기 위해 많은 연구자들이 초 
정 (pro-eutectic) 조직의 상(phase)의 크기를 측정하 는 방법을 사용하고 있다. A. Gain 등 ${ }^{23)}$ 은 $\mathrm{Sn}-\mathrm{Bi}-\mathrm{Ag}$ 솔더에 $\mathrm{Ni}$ 나노 입자를 첨가한 결과 나노입자로 강화 된 솔더에서 $\beta-\mathrm{Sn}$ 영역 및 $\mathrm{Ag} 3 \mathrm{Sn}$ 이 미세화된 것을 확인하였다. 미세화 된 이유로 유력한 것은 나노 $\mathrm{Ni}$ 입자가 $\mathrm{Sn}$ 과 반응하여 $\mathrm{Sn}-\mathrm{Ni} \mathrm{IMC}$ 를 형성하고, 이러 한 IMC 입자가 응고 시 고체 핵생성 사이트로 작용하 여 결정립 성장을 억제하기 때문인 것으로 보고되었다. 더불어 금속입자의 첨가가 과냉도를 줄여서 IMC 성장 억제 및 조직을 미세화하는 것으로 분석하고 있다. L. Shen 등 ${ }^{24}$ 도 $\mathrm{Sn}-\mathrm{Bi}$ 에 $\mathrm{Cu}$ 나노 입자를 첨가하는 연 구를 진행하여 나노 입자들은 입계를 고정하거나 구속 하는 작용을 하며, 나노입자 첨가율이 증가함에 따라 솔더의 상(phase)의 크기가 감소함을 확인하였다.

이렇게 상(phase)가 미세화되면 아래 (eq.1)의 HallPetch 식에 따라 솔더 기지의 강도가 증가한다 ${ }^{25)}$.

$$
\Delta \sigma_{\text {Hall }- \text { Petch }}=k_{y}\left(d_{m}\right)^{-1 / 2}
$$

$k_{y}$ : constant according to the material

$d_{m}:$ phase size of the solder matrix

\section{4. 접합계면의 금속간 화합물}

솔더링 중 용융된 솔더는 기판의 금속 패드나 비아홀 과 전자부품의 리드, 금속 전극부 사이의 틈새에 침투 하여 접합부의 계면에 금속간 화합물을 형성하면서 접 합을 이룬다. 모재 금속의 표면에 솔더가 퍼지면서 (wetting) 모재와 솔더 사이 원자간 이동이 발생하고, 이동한 원자간 결합으로 금속간 화합물이 생성되며, 용 융 솔더의 응고가 진행되면서 접합이 완료된다 ${ }^{26)}$. 이러 한 계면의 $\mathrm{IMC}$ 는 솔더링부의 기계적 강도와 수명에 지대한 영향을 미친다.

한 예로, $\mathrm{Sn}-58 \% \mathrm{Bi}$ 솔더에 $0.5 \mathrm{wt} \% \mathrm{In}$ 을 첨가하 면 솔더와 기판의 $\mathrm{Cu}$ 계면에 과도한 $\mathrm{Cu}_{6} \mathrm{Sn}_{5} \mathrm{IMC}$ 의 생성을 억제할 수 있다랄. $0.5 \mathrm{wt} \% \mathrm{Ni}$ 를 첨가하는 경우 에도 유사한 효과를 낼 수 있다라. A. Gain 등 ${ }^{23)}$ 은 $\mathrm{Cu}$ 기 판에 $\mathrm{Sn}-35 \% \mathrm{Bi}-1 \% \mathrm{Ag}-0.5 \% \mathrm{Ni}$ 를 솔더링한 후 $200^{\circ} \mathrm{C}$ 에서 $30 \mathrm{~min}$ 유지시켰다. 그 결과 $\mathrm{Sn}-35 \% \mathrm{Bi}-1 \% \mathrm{Ag}^{-}$ $0.5 \% \mathrm{Ni}$ 과 $\mathrm{Cu}$ 와의 계면에서 $\left(\mathrm{Cu}_{6} \mathrm{Sn}_{5}+\mathrm{Cu}_{3} \mathrm{Sn}\right) \mathrm{IMC}$ 층의 두께는 약 $3 \mu \mathrm{m}, \mathrm{Sn}-35 \% \mathrm{Bi}-1 \% \mathrm{Ag}$ 는 약 $4.8 \mu \mathrm{m}$ 로 $\mathrm{Sn}-35 \% \mathrm{Bi}-1 \% \mathrm{Ag}-0.5 \% \mathrm{Ni}$ 솔더가 $\mathrm{Sn}-35 \% \mathrm{Bi}-1 \% \mathrm{Ag}$ 솔더보다 $\mathrm{IMC}$ 층 두께가 감소했다. 또한, 동일조건에 서 $\mathrm{IMC}$ 의 성장 속도는 $\mathrm{Sn}-35 \% \mathrm{Bi}-1 \% \mathrm{Ag}-0.5 \% \mathrm{Ni}$ 가 $\mathrm{Sn}-35 \% \mathrm{Bi}-1 \% \mathrm{Ag}$ 에 비해 약 $36.4 \%$ 감소했으며, $200^{\circ} \mathrm{C}$ 에서 5 분 유지한 경우에는 약 $17.9 \%$ 감소했음 을 보고하였다. 아울러, 접합 온도 및 접합 온도에서의

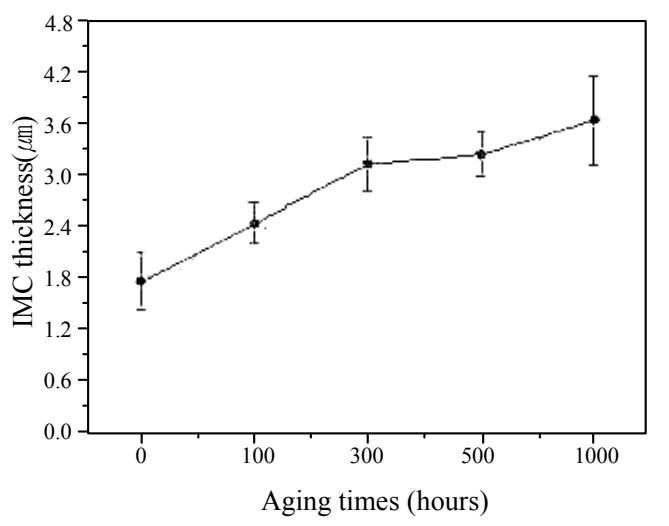

Fig. 2 IMC thickness in the solder joints as a aging time $^{27)}$

유지 시간 증가에 따라 $\mathrm{Cu}$ 와의 계면에서 $\mathrm{IMC}$ 의 두께 가 증가함을 보고하였다.

Shin 등27) 은 $\mathrm{Sn} 58 \mathrm{Bi}$ 솔더 페이스트와 ENIG 표 면 처리된 기판 접합부의 시효시간에 따른 계면의 IMC 성장 및 접합 강도에 관하여 보고하였다. 이들은 $\mathrm{Cu}$ 층 위에 $\mathrm{ENIG}$ 로 Ni-P 층을 $5 \mu \mathrm{m}, \mathrm{Au}$ 층을 $0.15 \mu \mathrm{m}$ 무전 해 도금하여, 금속간 화합물 층 두께를 $125^{\circ} \mathrm{C}$ 의 온도 에서 등온 시효 열처리 시간에 따라 측정하였다 (Fig. 2 참조). 금속간 화합물 (IMC) 층의 두께는 열처리 전에 는 약 $1.8 \mu \mathrm{m}$ 를 나타내었으며 열처리 시간이 증가함에 따라 점차 증가하여, 1000 시간 등온 시효 처리 이후에 는 약 $4 \mu \mathrm{m}$ 두께까지 성장하였다.

계면에서의 $\mathrm{IMC}$ 두께 성장은 아래 그림과 같은 실 험식 (eq. 2)으로 주어진다.

$$
X=\sqrt{D t}+X_{0}
$$

단, $\mathrm{X}$ 는 전체 IMC 두께, $\mathrm{X}_{0}$ 는 초기 IMC 두께, $\mathrm{t}$ 는 시 간, $\mathrm{D}$ 는 $\mathrm{IMC}$ 층의 확산 계수이다.

Y.Kim 등 28$)$ 은 $\mathrm{Sn} 58 \mathrm{Bi}$ 솔더의 기판측 $\mathrm{Cu}$ 패드의 표면처리에 따른 IMC 형상 변화에 대해 보고하였다. Fig. 3은 $85^{\circ} \mathrm{C} / 85 \mathrm{RH} \%$ 조건에서 1000 시간까지 시효 처리 (aging)한 후, 솔더를 모두 에칭해 제거하고 $\mathrm{Cu}$ 패드부측 접합 계면을 위에서 내려다본 형상이다. OSP (organic solder preservative) 표면처리의 경우 구상 의 미립자상의 $\mathrm{Cu}-\mathrm{Sn} \mathrm{IMC}\left(\mathrm{Cu}_{6} \mathrm{Sn}_{5}\right)$ 가 형성되었으 며, 1000 시간 시효 후에도 구상의 $\mathrm{Cu}_{6} \mathrm{Sn}_{5}$ 미립자의 크기는 큰 변화가 관찰되지 않았다. 반면 ENEPIG 처 리의 경우 접합 초기에 조대한 막대상의 $\mathrm{Ni}_{3} \mathrm{Sn}_{4} \mathrm{IMC}$ 가 형성되었으며, 1000 시간 시효 후에는 $(\mathrm{Ni}, \mathrm{Pd})_{3}(\mathrm{Sn}, \mathrm{Bi})_{4}$ $\mathrm{IMC}$ 로 막대상이 약간 더 성장되고, 표면에 미세한 요철 이 관찰되었다. $\mathrm{ENIG}$ 처리의 경우 다각형상의 $\mathrm{Ni}_{3} \mathrm{Sn}_{4}$ $\mathrm{IMC}$ 가 형성되었으며, $85^{\circ} \mathrm{C}$ 에서 1000 시간 시효 후에 


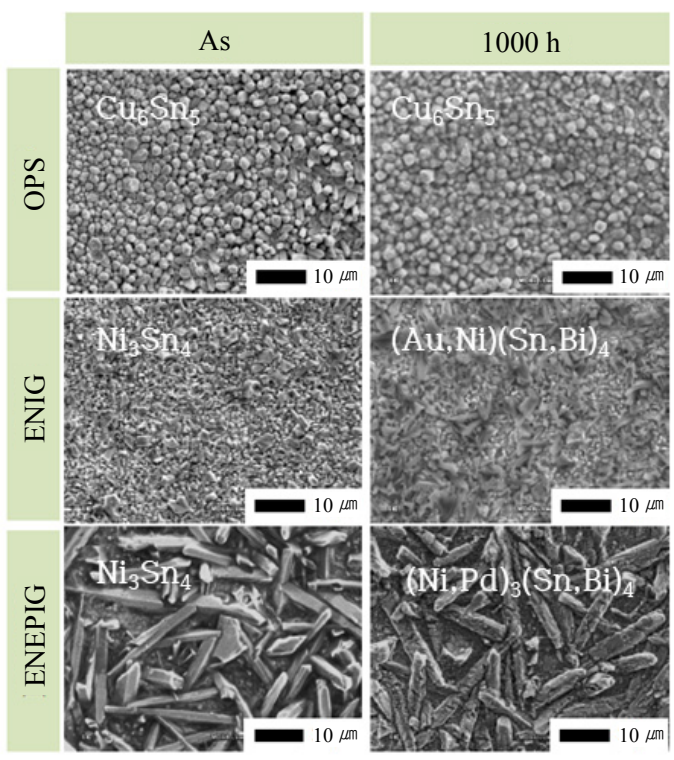

Fig. 3 Morphologies of etched IMC's with aging under $85^{\circ} \mathrm{C} / 85 \mathrm{RH} \%$ and various surface finishes ${ }^{28)}$

는 $(\mathrm{Au}, \mathrm{Ni})(\mathrm{Sn}, \mathrm{Bi})_{4} \mathrm{IMC}$ 가 약간 성장되었음을 보고 하였다.

\section{5. 기계적 강도}

Mokhtari 등 22)은 $0.5 \mathrm{wt} \% \mathrm{Ni}$ 및 $0.5 \mathrm{wt} \%$ In 첨 가로 $\mathrm{Sn}-58 \% \mathrm{Bi}$ 솔더 접합부의 전단 강도를 증가시킬 수 있음을 보고하였다. 또한 이들의 연구결과에 따르면 $0.5 \mathrm{wt} \% \mathrm{Ni}$ 을 첨가한 경우, $\mathrm{Ni}_{3} \mathrm{Sn}_{4} \mathrm{IMC}$ 의 솔더 내 형성으로 인해 $\mathrm{Sn}-58 \% \mathrm{Bi}$ 연신율이 감소하였다. 반면 $0.5 \mathrm{wt} \% \mathrm{In}$ 을 첨가한 경우, 딤플이 관찰되는 연성 파 면을 나타냄을 보고하였다. 특히 In을 첨가한 경우 가 장 큰 연신율을 나타내었다.

이들은 시효된 $\mathrm{Sn} 58 \mathrm{Bi}$ 솔더 접합부의 파괴는 $\mathrm{IMC}$ 를 따라 일어나는 것을 관찰하였으며 $0.5 \mathrm{In}$ 및 $0.5 \mathrm{Ni}$ 을 첨가한 $\mathrm{Sn} 58 \mathrm{Bi}$ 솔더 접합부의 파괴는 솔더/Cu 계 면 $\mathrm{IMC}$ 의 성장 억제로 솔더 내부 파괴를 일으킴을 확 인하였다. 또한 $\mathrm{Zn}$ 을 첨가하면 새로운 $\mathrm{CuZn}_{2}$ 상을 형 성하고 $\mathrm{Ni}$ 코팅 탄소 나노 튜브로 보강하면 인장강도와 연성이 향상되는 등 미세한 나노입자가 상(phase) 및 금속화합물 미세화에 영향을 주며, 이로 인해 솔더의 열적·기계적 특성, 미세경도, 크리프 저항성 등이 향상 됨이 보고되었다 ${ }^{30,31)}$.

Wang 등 ${ }^{18)}$ 은 $\mathrm{Sn}-38 \% \mathrm{Bi}-1.5 \mathrm{Sb}-0.7 \mathrm{Ag}$ 벌크 솔더 가 $\mathrm{Sn} 58 \mathrm{Bi}$ 솔더에 비해 더 높은 강도를 가지며, 연신 율은 유사함을 보고하였다 또한, 솔더 볼 전단 시험을 통해 $\mathrm{Sn}-38 \mathrm{Bi}-1.5 \mathrm{Sb}-0.7 \mathrm{Ag}$ 솔더가 $\mathrm{Sn} 58 \mathrm{Bi}$ 솔더에 비해 $125^{\circ} \mathrm{C}$ 에서 40 일까지 등온 시효 후 더 높은 전단
강도를 가짐을 확인하였다.

Shimokawa 등 ${ }^{29)}$ 은 $\mathrm{Sn}-57 \mathrm{wt} \% \mathrm{Bi}-1 \mathrm{wt} \% \mathrm{Ag}$ 솔더 의 고온 강도를 평가하였는데, $100^{\circ} \mathrm{C}$ 이하의 온도에서 $\mathrm{Sn} 57 \mathrm{Bi} 1 \mathrm{Ag}$ 는 $\mathrm{Sn} 37 \mathrm{~Pb}$ 에 비해 매우 우수한 크립 강 도를 나타내었다. 또한 $0 \sim 90^{\circ} \mathrm{C}$ 범위에서 1000 열사 이클 특성 시험 결과, $\mathrm{Sn} 37 \mathrm{~Pb}$ 에 비하여 발생한 균열 길이가 더 짧았다.

L. Shen 등 ${ }^{24)}$ 은 $\mathrm{Cu}$ 및 $\mathrm{Ni}$ 나노 입자를 첨가하여 나 노 입자 증가에 따라 $\mathrm{Sn} 58 \mathrm{Bi}$ 의 크립 저항성이 증가 함을 확인하였으며, 실험 결과 $3 \mathrm{wt} \% \mathrm{Cu}$ 와 $1 \mathrm{wt} \% \mathrm{Ni}$ 이 $\mathrm{Sn} 58 \mathrm{Bi}$ 솔더의 크립 저항성을 가장 크게 증가시키 는 것으로 보고하였다.

한편, K.Kim 등 32$)$ 은 $\mathrm{SAC} 305, \mathrm{Sn} 58 \mathrm{Bi}, \mathrm{Sn} 58 \mathrm{Bi}$ epoxy solder 3종류의 솔더에 따른 전단력을 보고하였 다 (Fig. 4 참조). Fig. 4에서 알 수 있듯이 SAC305, $\mathrm{Sn} 58 \% \mathrm{Bi}$ 그리고 에폭시 $\mathrm{Sn} 58 \mathrm{Bi}$ 솔더의 전단력은 각 각 $2.15 \mathrm{~N}, 2.73 \mathrm{~N}$ 및 $4.88 \mathrm{~N}$ 의 값을 가졌다. 이때 에 폭시 $\mathrm{Sn} 58 \mathrm{Bi}$ 솔더의 전단력이 매우 높은 것은 솔더 주위에 형성된 에폭시 필렛이 솔더 볼을 지지해주기 때 문이라고 보고하였다. 이들은 $\mathrm{SAC} 305, \mathrm{Sn} 58 \mathrm{Bi}$, 에 폭시 $\mathrm{Sn} 58 \mathrm{Bi}$ 솔더에 대해 낙하 시험을 실시하였는데 그 결과 $\mathrm{SAC} 305, \mathrm{Sn} 58 \mathrm{Bi}$, 에폭시 $\mathrm{Sn} 58 \mathrm{Bi}$ 의 낙하충 격횟수는 각각 95 회, 3 회, 185 회의 값을 가졌다. 따라 서 낙하충격횟수는 전단 파괴에너지 경향과 일치함을 밝혔다. 에폭시 강화 솔더를 사용한 OSP 처리 기판이 $\mathrm{ENIG}$ 와 ENEPIG 처리 기판에 비해 파괴 시까지 가 장 많은 낙하 횟수를 기록하였다. 또한, Y.Kim 등 28$)$ 은 $\mathrm{SAC} 305, \mathrm{Sn} 58 \mathrm{Bi}$, 에폭시 $\mathrm{Sn} 58 \mathrm{Bi}$ 솔더에 대해 기판 의 $\mathrm{Cu}$ 패드 표면처리 및 $85^{\circ} \mathrm{C}$ 에서 시효시간에 따른 전단 시험을 실시하였다 (Fig. 5 참조). 이들에 의하면 $\mathrm{Sn} 58 \mathrm{Bi}$, 에폭시 $\mathrm{Sn} 58 \mathrm{Bi}$ 솔더 모두 전단강도는 $\mathrm{OSP}>\mathrm{ENIG}$ $\fallingdotseq \mathrm{ENEPIG}$ 순서로 감소되었다.

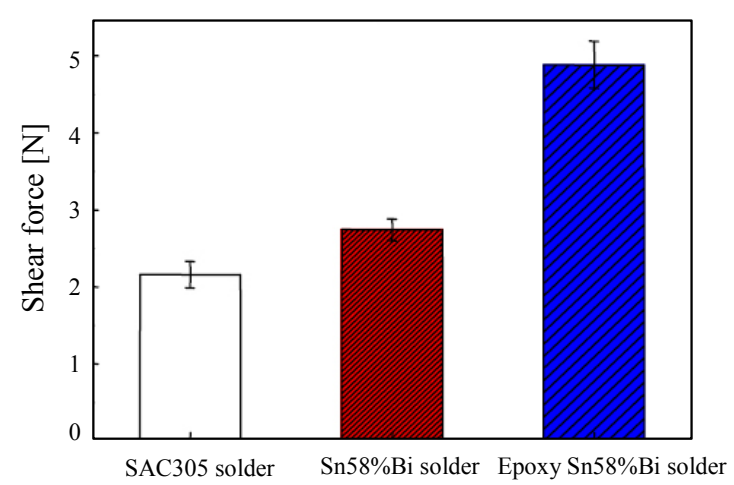

Fig. 4 Shear force of the $\mathrm{Sn} 58 \% \mathrm{Bi}$ solder joints compared with that of SAC $305^{32)}$ 

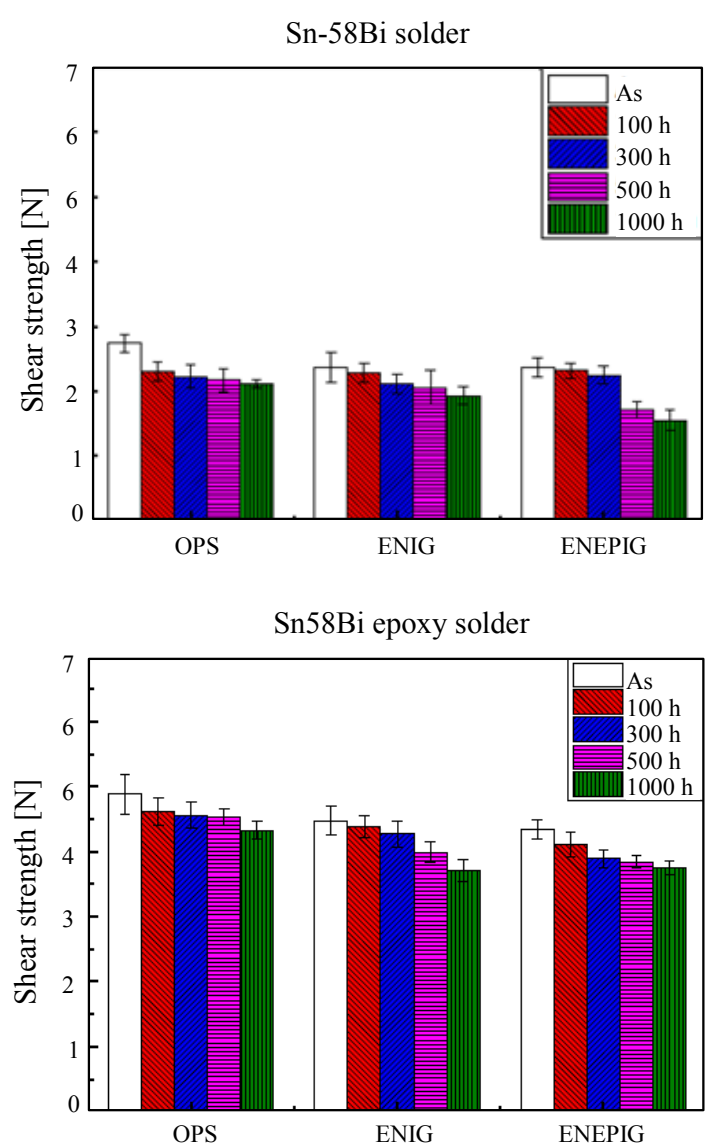

Fig. 5 Shear strength of Sn $58 \% \mathrm{Bi}$ and $\mathrm{Sn}-58 \% \mathrm{Bi}$ epoxy solder with various surface finishes and aging time $^{28)}$

\section{6. 결 론}

최근 전자부품의 플렉서블 기판의 증가 및 대형화로 인한 열변형 방지를 위하여 저온 솔더에 대한 요구가 높아지면서 저온 솔더의 대표격인 $\mathrm{Sn} 58 \mathrm{Bi}$ 계의 강도, 융점, 연성 개선 등에 대한 연구가 활발하다. 최근의 연구 결과를 정리해보면 현재는 $\mathrm{Sn} 58 \mathrm{Bi}$ 에 In 및 $\mathrm{Ag}$ 첨가를 통하여 $\mathrm{Sn} 58 \mathrm{Bi}$ 의 융점 강하 효과를 거두고 있 다. 기존 $\mathrm{Sn} 58 \mathrm{Bi}$ 무연 솔더에서 조대한 $\mathrm{Bi}$ 로 인해 발 생하는 단점인 취성을 개선하고 연성 및 인성을 향상시 켜 취성 파괴 발생을 억제하고 있으며, 이외에도 $\mathrm{Cu}$, $\mathrm{Ni}$ 등 다양한 원소를 소량 첨가하여 $\mathrm{Bi}$ 및 $\beta-\mathrm{Sn}$ 상을 미세화하는 연구들이 계속해서 발표되고 있다. 또한 이 들 첨가 원소들은 접합 계면의 금속간 화합물 (IMC) 성장을 억제하여 취성인 $\mathrm{IMC}$ 를 따라 파괴되는 정도를 줄이고, 연성인 솔더를 통해 파괴되는 경향을 증가시키 는 바람직한 현상을 유도한다. 아울러, 기판 표면의 표면 처리에 따른 $\mathrm{IMC}$ 형상 변화도 연구되고 있는데 OSP 및 $\mathrm{ENIG}$ 가 $\mathrm{ENEPIG}$ 보다 우수한 결과를 보이고 있
다. 또한 에폭시 강화 $\mathrm{Sn} 58 \mathrm{Bi}$ 솔더를 사용함으로써 전단강도 및 낙하강도를 증가시킬 수 있다는 연구 결과 도 있다. 이처럼 $\mathrm{Sn} 58 \mathrm{Bi}$ 솔더에 대한 다양한 개선 노 력에도 불구하고 아직도 더 큰 연성과 인성, 낙하, 휨 특성 등이 요구되고 있어, 앞으로도 $\mathrm{Sn}-\mathrm{Bi}$ 저온 솔더 에 대한 지속적인 연구가 필요하다.

사 사

이 논문은 과학기술정보통신부와 산업통상자원부가 공 동 지원한 '나노융합2020사업(www.nanotech2020.org)' 으로 지원을 받아 수행된 연구 결과입니다. 〔과제명:자동 차 전장 및 플렉서블 부품 접합용 고연성 저온 나노분산 솔더페이스트 기술개발 / 과제고유번호: R201901710]

ORCID: Hyejun Kang: https://orcid.org/0000-0002-8903-6258 ORCID: Jae Pil Jung: https://orcid.org/0000-0002-4526-0442

\section{References}

1. C. S. Kang and J. P. Jung, Micro-Joining, Samsung books, Seoul, Korea , ISBN 89-88197-51-8, (2004) 4.

2. M. Abtew and G. Selvaduray, Lead-free solders in microelectronics, Mater. Sci. Eng. R, 27 (5-6) (2000) 95-141. https://doi.org/10.1016/S0927-796X(00)00010-3

3. R. W. Johnson, J. L. Evans, P. Jacobsen, J. R. Thompson and M. Christopher, The Changing Automotive Environment, High-Temperature Electronics, IEEE Trans. Electron. Packag. Manuf. 27(3) (2004) 164-176.

https://doi.org/10.1109/TEPM.2004.843109

4. A. K. Gain, Y. C. Chan, K. C. Yung, A. Sharif and L. Ali, Effect of Nano Ni Additions on the Structure and Properties of Sn-9Zn and Sn-8Sn-3Bi Solder in Ball Grid Array Packages, 2nd Electronics System integration Technology Conference, Greenwich, UK, (2008) IEEE, ISBN 9781424428137, 1291-1294. https://doi.org/10.1109/ESTC.2008.4684540

5. K. Suganuma, S. J. Kim and K. S. Kim, High-Temperature Lead-Free Solders, Properties and Possibilities, The Minerals, Met. Mater. Soc. 61(1) (2009) 64-71. https://doi.org/10.1007/s11837-001-0097-5

6. Y. Plevachuk, W. Hoyer, I. Kaban, M. Ko“hler and R. Novakovic, Experimental study of density, surface tension, and contact angle of Sn-Sb-based alloys for high temperature soldering, J. Mater. Sci. 45 (2010) 2051-2056. https://oi.org/10.1007/s10853-009-4120-5

7. M. Kamal and El. S. Gouda, Effect of zinc additions on structure and properties of Sn-Ag eutectic lead-free solder alloy, J. Mater. Sci. Mater. Electron. 19 (2008) 81-84. https://doi.org/0.1007/s10854-007-9289-2

8. A. K. Gain, T. Fouzder, Y. C. Chan and W. K. C. Yung, Microtructure, kinetic analysis and hardness of Sn-Ag- 
$\mathrm{Cu}-1$ wt $\%$ nano- $\mathrm{ZrO}_{2}$ composite solder on OSP-Cu pads, J. Alloys Compd. 509(7) (2011) 3319-3325.

https://doi.org/10.1016/j.jallcom.2010.12.048

9. I. E. Anderson, Development of Sn-Ag-Cu and Sn-Ag$\mathrm{Cu}-\mathrm{X}$ alloys for $\mathrm{Pb}$-free electronic solder applications, J. Mater. Sci. Mater. Electron. 18 (2007) 55-76. https://doi.org/10.1007/s10854-006-9011-9

10. L. Liu, P. Wu and W. Zhou, Effects of $\mathrm{Cu}$ on the interfacial reactions between $\mathrm{Sn}-8 \mathrm{Zn}-3 \mathrm{Bi}-\mathrm{xCu}$ solders and $\mathrm{Cu}$ substrate, Microelectronics Reliability, 54(1) (2014) 259-264.

https://doi.org/10.1016/j.jallcom.2009.04.003

11. H. R. Kotadia, P. D. Howes, S. H. Mannan, On the development of low melting temperature $\mathrm{Pb}$-free solders, Microelectron. Reliab. 54(6-7) (2014) 1253-1273. https://doi.org/10.1016/j.microrel.2014.02.025

12. J. P. Jung, Y. E. Shin and S. S. Lim, Pb-free Micro Soldering, Samsung books, Seoul, Korea, ISBN 89-8819743-7, (2005) 8.

13. J. P. Jung, Y. E. Shin, S. S. Lim, Pb-free Micro Soldering, Samsung books, Seoul, Korea, ISBN 89-88197-43-7, (2005) 11.

14. W. Dong, Y. Shi, Z. Xia and Y. Lei, F. Guo, Effects of trace amounts of rare earth additions on microstructure and properties of Sn-Bi-based solder alloy, J. Electron. Mater. 37 (2008) 982-991. https://doi.org/10.1007/s11664-008-0458-8

15. Z. Wang, Q. K. Zhang, Y. X. Chen and Z. L. Song, Influences of $\mathrm{Ag}$ and In alloying on Sn-Bi eutectic solder and $\mathrm{SnBi} / \mathrm{Cu}$ solder joints, J. Mater. Sci. Mater. Electron. 30 (2019) 18524-18538. https://doi.org/10.1007/s10854-019-02206-y

16. C. Zhang, S. D. Liu, G. T. Qian, J. Zhou, F. Xue, Effect of Sb content on properties of Sn-Bi solders, Trans. Nonferrous Met. Soc. China, 24 (2014) 184-191 https://doi.org/10.1016/S1003-6326(14)63046-6

17. J. Xu, H. He, F. Zhang, Z. Zhao and Hu, Study of Sn-Bi-Cu Lead-free Solder, 10th Electronics Packaging Technology Conference (EPTC), IEEE, 9-12 December 2008, Singapore, (2008) 1375-1380. https://doi.org/10.1109/EPTC.2008.4763623

18. K. Wang, F. Wang, Y. Huang, K. Qi, Comprehensive Properties of a Novel Quaternary Sn-Bi-Sb-Ag Solder, Wettability, Interfacial Structure and Mechanical Properties, Met. 9(7) (2019) 791. https://doi.org/10.3390/met9070791

19. Y. E. Shin, S. S. Lim and J. P. Jung, Soldering, Samsung books, Seoul, Korea, ISBN 89-88197-16-X, (2002) 13.

20. H. W. Miao and J. G. Duh, Microstructure evolution in Sn-Bi and Sn-Bi-Cu solder joints under thermal aging, Mater. Chem. Phys. 71(3) (2001) 255-271. https://doi.org/10.1016/S0254-0584(01)00298-X

21. S. Sakuyama, T. Akamatsu, K. Uenishi and T. Sato, Effects of a third element on microstructure and mechanical properties of eutectic Sn-Bi solder, Trans. Japan Inst.
Electron. Packag. 2(1) (2009) 98-103.

https://doi.org/10.5104/jiepeng.2.98

22. O. Mokhtari and H. Nishikawa, Correlation between microstructure and mechanical properties of Sn-Bi-X solders, Mater. Sci. Eng. A, 651 (2016) 831-839. https://doi.org/10.1016/j.msea.2015.11.038

23. A. K. Gain and L. Zhang, Interfacial microstructure, wettability and material properties of nickel (Ni) nanoparticle doped tin-bismuth-silver (Sn-Bi-Ag) solder on copper $(\mathrm{Cu})$ substrate, J. Mater. Sci. Mater. Electron. 27 (2016) 3982-3994.

https://doi.org/10.1007/s10854-015-4252-0

24. L. Shen, Z. Y. Tan and Z. Chen, Nanoindentation study on the creep resistance of $\mathrm{SnBi}$ solder alloy with reactive nano-metallic fillers, Mater. Sci. Eng. A, 561 (2013) 232-238. https://doi.org/10.1016/j.msea.2012.10.076

25. W. D. Callister and D. G. Rethwisch, Fundamentals of Materials Science and Engineering (2nd edition) Wiley and Sons, Singapore, (2000) 252.

26. Micro-soldering and Joining Technology, MPC, Korea Welding \& Joining Society, Ace Inc., (2018) 5-10, ISBN 979-11-89547-00-4.

27. H. P. Shin, B. W. Ahn, J. H. Ahn, J. G. Lee, K. S. Kim, D. H. Kim and S. B. Jung, Interfacial Reaction and Joint Strength of the Sn-58\%Bi Solder Paste with ENIG Surface Finished Substrate, J. Korean Weld. Join. Soc. 30(5) (2012) 458-463. https://doi.org/10.5781/KWJS.2012.30.5.458

28. Y. Kim, The improvement of bonding strength with an addition of epoxy and the effects of various surface finishes on $\mathrm{Sn}-58 \% \mathrm{Bi}$ epoxy solder, $13^{\text {th }}$ International Symposium on Microelectronics and Packaging (ISMP), Seoul, Korea, KMEPS (2014).

29. H. Shimokawa, T. Soga, K. Serizawa, K. Katayama and I. Shohji, Evaluation on mechanical properties of Sn-Bi-Ag solder and reliability of the solder joint, Trans of JIEP, 8(1) (2015) 46-54.

https://doi.org/10.5104/jiepeng.8.46

30. J. Shen, Y. Pu, H. Yin, D. Luo and J. Chen, Effects of minor $\mathrm{Cu}$ and $\mathrm{Zn}$ additions on the thermal, microstructure and tensile properties of Sn-Bi-based solder alloys, J. Alloys Compd. 614 (2014) 63-70. https://doi.org/10.1016/j.jallcom.2014.06.015

31. L. Z. Yang, W. Zhou, Y. H. Liang, W. Q. Cui and P. $\mathrm{Wu}$, Improved microstructure and mechanical properties for Sn58Bi solder alloy by addition of Ni-coated carbon nanotubes, Mater. Sci. Eng. A, 642 (2015) 7-15. https://doi.org/10.1016/j.msea.2015.06.080

32. K. Y. Kim, H. S. Jeong, W. R. Myung and S. B. Jung, Microstructures and Drop Impact Test of SAC305, Sn58\%Bi and Epoxy Sn58\%Bi Solder Joint on the OSP Surface Finished PCB Substrate, JWJ. 36(2) (2018) 14-200. 
https://doi.org/10.5781/JWJ.2018.36.2.3

33. B. J. Lee, C. S. Oh and J. H. Shim, Thermodynamic assessments of the Sn-In and Sn-Bi binary systems, $J$. Electron. Mater. 25 (1996) 983-991.

https://doi.org/10.1007/BF02666734
34. S. N. ALAM, N. JINDAL and N. NAITHANI, Effect of addition of $\mathrm{Cu}$ on the properties of eutectic $\mathrm{Sn}-\mathrm{Bi}$ solder alloy, Mater. Sci. Poland, 37(2) (2019) 212-224. https://doi.org/10.2478/msp-2019-0032 